\title{
Improving Plant-Based Genotoxicity Bioassay for Trace Metal-Contaminated Water: Insights from Myriophyllum Aquaticum (Vell.) Verdc. and Cd.
}

\section{Andrea Coppi}

Universita degli Studi di Firenze

llaria Colzi ( $\boldsymbol{D}$ ilaria.colzi@unifi.it )

Universita degli Studi di Firenze https://orcid.org/0000-0001-9901-2164

Lorenzo Lastrucci

Universita di Firenze: Sistema museale di Ateneo

Maria Beatrice Castellani

Universita degli Studi di Firenze

Cristina Gonnelli

Universita degli Studi di Firenze

\section{Research Article}

Keywords: AFLP, aquatic plants, bioassays, genotoxicity, trace metals

Posted Date: May 27th, 2021

DOI: https://doi.org/10.21203/rs.3.rs-498949/v1

License: (9) This work is licensed under a Creative Commons Attribution 4.0 International License.

Read Full License 


\section{Abstract}

In this work, we evaluated whether the species Myriophyllum aquaticum (Vell.) Verdc. can be a promising material for devising reliable ecotoxicological tests for $\mathrm{Cd}$ contaminated waters. Plants of $M$. aquaticum were exposed to $\mathrm{Cd}$, using different concentrations and exposure times, in order to address as many possible effects as possible of its presence. Plant growth and $\mathrm{Cd}$ accumulation were monitored along the treatment period and Cd genotoxicity was assessed by analyzing Cd-induced changes in the AFLP fingerprinting profiles. Root and shoot growth was reduced already at the lowest Cd concentration used (1 $\left.\mathrm{mg} \mathrm{L}^{-1}\right)$. Shoots showed a higher $\mathrm{Cd}$ sensitivity and a lower accumulation, thus being chosen as the more suitable organ for the genotoxic analysis. DNA variation was observed starting from $2.5 \mathrm{mg} \mathrm{L}^{-1}$, indicating that the metal-induced depression of plant growth at the lower concentration did not necessarily imply a genotoxic effect. Similar results were obtained in the time-dependent experiment, since Cd effect on DNA fingerprinting profile was observed after three days of exposure and without a significant growth decrease growth. Therefore, our results showed that $M$. aquaticum proved to be a suitable model system for the investigation of Cd genotoxicity through AFLP fingerprinting profile, whereas the more classic eco-toxicological tests based only on biometric parameters could underestimate the risk associated to undetected Cd genotoxicity.

\section{Introduction}

Over the past decades, intensive industrialization and agriculture have increased considerably the release of various toxic compounds into air, soil and water, causing many environmental problems (Khan and Ghouri 2011). Among the most common contaminants, trace metals are of serious concern, since, unlike organic toxins, they are non-biodegradable and accumulate in the environmental matrixes (Ali et al. 2013). Water, the key vital resource for natural ecosystems and human life, is subjected to a continuous anthropogenic input of these elements, that can thus freely reach any kind of biota (Schwarzenbach et al. 2006). Therefore, the development of scientifically-sound and cost-efficient tools for the contaminant monitoring is a priority for the overall protection of all living organisms, along with the pressing necessity to restore the polluted aquatic ecosystems and to clean the contaminated wastewaters.

Among the monitoring tools, effect-based methods, such as bioassays and biomarkers, are widely employed because their unique ability to fill the gap between chemical pollution and ecological status, covering a broad range of exposure times and toxicity mechanisms in diverse biological systems (Brack et al. 2017). Test organisms include invertebrates, fishes, microorganisms, plants and algae, even though some of them can be difficult to handle and their use may be ethically objectionable. Other systems, such as mammalian cells, are expensive and results are not always consistent (Hassan et al. 2016). Nonetheless, the use of aquatic plants as biological models in eco-toxicological tests is limited if compared to animals, although contaminants mainly enter the ecosystem through such organisms, that are the first and obligate step of the trophic chains (Ceschin et al. 2020). 
Over the last years, increasing attention has been paid to bioassays for the assessment of trace metal genotoxic effects, since the interaction with nucleic acids is considered one of the primary causes of the toxicity of such elements (Kleinjans and van Schooten 2002; Zhu and Costa 2020). Actually, only if the conduction of genotoxicity assays is added to the analysis of conventional water quality parameters, the presence of mutagens in water is considered to be reliably assessed (Ohe et al. 2004). As for the test organisms, plants are regarded as ideal assay systems for screening and monitoring mutagens in the environment, providing vital information from the viewpoint of preserving biodiversity and ecological resources (Panda and Panda 2002; Aksoy 2017). Plant organisms are affected by water pollution earlier than other organisms, since they are the first interface between abiotic and biotic constituents of an ecosystem and, therefore, considered as early warning systems, essential for intercepting contaminations in advance (Ceschin et al. 2020). The development of molecular biology has led to several PCR-based techniques used to evaluate DNA damage in toxicological studies with plants as model systems. Those techniques include analysis of microsatellite markers (Monteiro et al. 2009), random amplified polymorphic DNA assay (Liu et al. 2009; Surgun-Acar et al. 2018) and analysis of amplified fragment length polymorphism (AFLP). In plant research, AFLP is already a powerful tool with broad applications in population genetics, linkage mapping, phylogeny, and biogeography (Meudt and Clarke 2007). More recently, AFLP has been used to screen plant genomic DNA for evidence of mutational events induced by environmental contaminants (Labra et al. 2003; Xue-mei et al. 2006; Aina et al. 2007; Coppi et al. 2018). In addition, AFLP can offer the possibility of detecting large portions of the genome at the populational level at relatively low cost (Caballero et al. 2013).

Among the most dangerous mutagens, cadmium (Cd) is one of the trace elements arising more concern for the environment and human health (ATSDR 2005), thus needing to be extensively studied and monitored for its public health effects (ATSDR 2015; USEPA 2015). The genotoxicity of Cd, classified as human carcinogen (IARC 2016), is supposed to derive from its direct binding to DNA, possibly at adenine, guanine and thymine (Hossain and Hug 2002), or direct inhibition of DNA mismatch repair (Jin et al. 2003). The Cd genotoxic effect may also be indirect, through generation of reactive oxygen species, which may then damage nucleic acids (Apel and Hirt 2004; Valverde and Rojas 2001). Several studies have demonstrated Cd-induced micronuclei formation, chromosomal aberrations or DNA base damage (Beyersmann and Hartwig 2008). Therefore, the assessment of genotoxicity of metals like Cd is an important topic in environmental research, with the increasing need of devising ecotoxicological tests sensitive to both concentration and exposure time to capture and address any possible effect of its presence. To this aim, we performed a toxicity test to assess if the species Myriophyllum aquaticum (Vell.) Verdc. can be a promising model system to propose to the eco-toxicologist scientific community in the view of devising reliable bioassays for $\mathrm{Cd}$ genotoxicity in waters. Myriophyllum aquaticum is a macrophyte native from Tropical and Subtropical America. We chose this species because of its unique advantages of yearly availability, large occurrence, easy to handle and to grow without the need of sterile conditions or expensive materials. Furthermore, an aquatic species can represent per se a more suitable model system for the evaluation of the genotoxic potentiality of contaminated waters, whereas generally such kinds of bioassays are unconcernedly performed on land plants. In addition, this plant can be easily 
propagated in a vegetative way, thus giving a living material with low level of genetic differentiation, that should be more reliable in revealing variation in its genetic structure when exposed to $\mathrm{Cd}$. Considering $M$. aquaticum as a promising model system, we assessed the changes caused by toxic Cd concentration on its AFLP fingerprinting profiles, at different doses and times of exposure. We moreover tested if one of the response traits of plants to the exposure of toxic concentration of $\mathrm{Cd}$ (e.g. plant growth), is time-coupled to evident genotoxic effect. Therefore, our results could provide fundamental information not only to devise more reliable eco-toxicological tests but also on the still poorly known Cd genotoxic effects on plants.

\section{Materials And Methods}

\subsection{Plant material sampling and acclimation conditions}

Stems of M. aquaticum were collected from Lago di Porta (PO) (see Lastrucci et al. 2017 and references therein) and cultivated in tap water as described in Colzi et al. (2018). After one week of acclimation in a greenhouse, plants were propagated by cutting apical segments of uniform size (about $5 \mathrm{~cm}$, three internodes) and cultivated in deionized water in 10 - L tanks in a growth chamber $\left(24 / 16^{\circ} \mathrm{C}\right.$ day/night; light intensity $100 \mu \mathrm{mol} \mathrm{m} \mathrm{m}^{-2} \mathrm{~s}^{-1}, 12 \mathrm{~h} \mathrm{~d}^{-1}$; relative humidity 60-65\%). After two weeks of acclimation, homogeneous plants (about $2 \mathrm{~g}$ f.w.) were selected for the following experimental procedures.

\subsection{Experiment 1: Cd treatment at different metal concentrations}

60 plants were transferred in 1-L polyethylene pots (one plant per pot, 12 pots per treatment) containing control solutions alone or added with 1, 2.5, 5 and $10 \mathrm{mg} \mathrm{L}^{-1}$ of $\mathrm{Cd}$, administered as $\mathrm{CdSO}_{4}$. Media and procedures for the experiments were adapted from OECD protocols for M. spicatum (OECD 2014). Exposure duration was shortened to seven days to intercept in advance possible genotoxic effects. The treatment levels were selected to have, in the plant-growth solutions, $\mathrm{Cd}$ concentrations exceeding the guidance levels for water quality standard in surface freshwater, established by national legislation (D.Igs. 152/2006). Furthermore, we used Cd concentrations in the same range of Wang et al. (2020), who showed them as environmentally significant, in addition to two higher concentrations ( 5 and $10 \mathrm{mg} \mathrm{L}^{-1}$ ), since, reviewing the literature, $\mathrm{Cd}$ concentrations in wastewaters was found as high as $20 \mathrm{mg} \mathrm{L}^{-1}$ (Salameh et al, 2018). The pots were maintained in the growth chamber for all the duration of the treatment and after seven days of exposure the plants were sampled for growth evaluation, determination of metal concentration and molecular analysis.

\subsection{Experiment 2: Cd treatment at different exposure times}

96 plants were transferred in 1-L polyethylene pots (one plant per pot, 12 pots per treatment) containing control solutions alone or added with $2.5 \mathrm{mg} \mathrm{L}^{-1}$ of $\mathrm{Cd}$ administered as $\mathrm{CdSO}_{4}$. The $\mathrm{Cd}$ dose used for the treatment was established from the results of the previous experiment at different concentrations. 
The pots were maintained in the growth chamber for all the duration of the treatment, removing plants from the test solution after 3, 7, 14 and 21 days of exposure.

\subsection{Growth measurement and determination of $\mathrm{Cd}$ concentration}

Root and shoot length and fresh weight of each plant were measured prior and after $\mathrm{Cd}$ treatment to evaluate plant response to $\mathrm{Cd}$ concentration and time exposure in terms of increment in plant growth. Subsequently, each sample was incubated in ice-cold $\left(4^{\circ} \mathrm{C}\right) \mathrm{Pb}\left(\mathrm{NO}_{3}\right)_{2}(10 \mathrm{mM})$ for $30 \mathrm{~min}$, as in Barzanti et al. (2011), to remove the adsorbed metal from the cell wall, and rinsed with milliQ-water. Roots and shoots were then divided and oven-dried for $24 \mathrm{~h}$ at $80^{\circ} \mathrm{C}$. For the $\mathrm{Cd}$ concentration analysis, aliquots of oven-dried material were weighted (about $100 \mathrm{mg}$ ) and mineralized with concentrated $\mathrm{HNO}_{3}(65 \%)$ at $200^{\circ} \mathrm{C}$ for $20 \mathrm{~min}$ in a microwave digestion system (Mars 6, CEM, Matthews, North Carolina, USA) as in Bettarini et al. (2019). After digestion, the solutions were adjusted to a volume of $25 \mathrm{~mL}$ with deionized water and $\mathrm{Cd}$ concentrations were determined by atomic absorption spectrophotometry (AAnalyst 200, Perkin Elmer). Certified reference materials (LGC No 7162) were used to verify the accuracy and the precision of the methods.

\subsection{DNA isolation and AFLP protocol}

A portion of shoot material (apex) was sampled from each plant, after growth measurements, from both experiment 1 and $2.30 \mathrm{mg}$ of each dried plant portion were ground in a mortar with sterile sand. The DNA was extracted by using the 2xCTAB protocol (Doyle and Doyle 1990). The quality and quantity of the extracted DNA was checked by a spectrometric survey that used a Bio-Photometer (Eppendorf). The AFLP analysis followed standard procedure with minor modifications (Coppi et al. 2018 and references therein). In order to screen the primers combination that produces the most informative, readable, and repeatable profiles, three primer pair combinations (Table 1) were tested on at least of three individuals from each sampling group.

Table 1

List of primer tested for the AFLP analysis. Fluorescent labelling and sequence with selective extension (in brackets) were also added.

\begin{tabular}{|lll|}
\hline Fluorescent end-labelling & Primer name & Primer sequence \\
\hline & PMsel_ATG & GATGAGTCCTGAGTAA(ATG) \\
\hline PMsel_TTC & GATGAGTCCTGAGTAA(TTC) \\
\hline 5'hexachloro-fluorescein- phosphoramidite & hex_pEcoRI_ACG & GACTGCGTACCAATTC(ACG) \\
\hline 5' 6-fluorescein amidite & fam_pEcoRI_TAC & GACTGCGTACCAATTC(TAC) \\
\hline
\end{tabular}


Two pairs of primers were selected for the final analysis: famEcoRl $\mathrm{I}_{(\mathrm{TAC})} / \mathrm{Msel}_{(\mathrm{ATG})}$ and $\operatorname{hexEcoRI}_{(A C G)} /$ Msel $_{(A T G)}$

\subsection{Analysis of genetic variation at intra- and inter-sampling group level}

Within-sampling group, average genetic diversity was expressed as the computed probability that two randomly chosen homologous sites are different (Nei 1987) by using the program Arlequin v2.000 (Schneider et al. 2000). Genomic template stability was evaluated confronting the differences in percentage of polymorphic bands composition for each sample. The percentage composition of polymorphic bands was calculated as [(nfrag/ntotal)*100], where nfrag was AFLP loci detected for each sample and ntotal the number of total detected bands. The identification of specific loci ( $\mathrm{SpL}$ ) was also performed. The SpL were identified as those shared into the control group and those for the treated group for both experiments. Analysis of molecular variance (AMOVA, Excoffier et al. 1992), implemented in Arlequin v2.000 (Schneider et al., 2000), was used to analyze the partitioning of total genetic variation within each sampling group and among sampling groups. The analyses were performed separately for the experiment 1 and 2 . Statistical support for the different hypothetical groupings of sampling group, based on treatment, was tested in terms of the variance components and the percentage of explained variation. Genetic distances between sampling groups were estimated by computing a Slatkin's linearized pairwise Fst matrix (Slatkin 1995), which was then used to generate a neighbour-joining (Saitou and Nei 1987) dendrogram with the software Mega 6 (Tamura et al. 2013).

\subsection{Statistics}

Statistical analysis was carried out with one-way ANOVA using the statistical program SPSS 13.0 (SPSS Inc. Chicago, IL, USA). A posteriori comparison of individual means was performed using Tukey's test.

Custom-made worksheets and program files for SigmaPlot 10.0 (SPSS, Chicago, IL) were used for the analysis of toxicity data. The half-maximal effective concentration was calculated on both the Cd concentration present in the medium and in the plant tissues. Reports about plant response to metals only rarely estimate sensitivity using quantitative parameters based on the internal concentration (Galardi et al. 2007; Colzi et al. 2011, 2014), whereas such calculation is necessary for studying the relationship between metal toxicity and accumulation.

\section{Results}

\subsection{Plant growth and Cd accumulation}

Data on plant growth and $\mathrm{Cd}$ accumulation in roots and shoots of $M$. aquaticum after $\mathrm{Cd}$ exposure are reported in Fig. 1A, B. The presence of the metal induced a significant reduction in both root and shoot length increment starting from the lowest concentration used. A significant fitting of root and shoot growth data to a logistic dose-response equation was obtained $(P<0.001, R=0.96$ for roots, $P<0.001, R$ 
$=0.91$ for shoots). For a quantitative estimation of $\mathrm{Cd}$ effect on plant growth, the parameter $\mathrm{EC}_{50 \mathrm{ext}}$ was calculated on external Cd concentration. The obtained values were $2.5 \pm 0.5 \mathrm{mg} \mathrm{L}^{-1}$ for roots and $2.0 \pm$ $0.5 \mathrm{mg} \mathrm{L}^{-1}$ for shoots, and were not significantly different between them.

Cadmium concentrations in both roots and shoots of $M$. aquaticum increased with increasing metal exposure (Fig. 1B), reaching values of about 1600 and $1200 \mu \mathrm{g} \mathrm{g}^{-1}$ d.w., respectively, at the highest level of exposure used. Cadmium accumulation in the roots was always significantly higher than in the shoots (at least $p<0.05$ ).

The parameter $\mathrm{EC}_{50}$ was calculated also on the basis of internal $\mathrm{Cd}$ concentration $\left(\mathrm{EC}_{50 \mathrm{int}}\right)$, using root and shoot accumulation data. As for external $\mathrm{Cd}$ concentration, the data fitting gave significant results for a logistic dose-response relationship ( $P<0.001, R=0.97$ for roots, $P<0.0001, R=0.91$ for shoots $)$ and the value of $E_{50 \text { int }}$ was significantly higher for roots $\left(974 \pm 34 \mu \mathrm{g} \mathrm{g}^{-1} \mathrm{~d}\right.$.w. $)$ than for shoots $(785 \pm 71 \mu \mathrm{g}$ $\mathrm{g}^{-1}$ d.w.).

In the experiment 2, plant growth and $\mathrm{Cd}$ accumulation at a fixed $\mathrm{Cd}$ concentration $\left(2.5 \mathrm{mg} \mathrm{L}^{-1}\right)$ was monitored over different exposure times, until 21 days (Fig. 2A, B). The presence of $\mathrm{Cd}$ in the solution started to produce a significant reduction in root and shoot growth after seven days of exposure (Fig. 2A).

Regarding Cd accumulation, both roots and shoots showed an increase in metal concentration with time, following a saturating trend. Starting from seven days of exposure, Cd concentrations were always significantly higher in roots than in shoots (at least $p<0.01$ ), reaching values about 2.5 -fold higher after 14 and 21 days.

\subsection{Analysis of AFLP profiles}

AFLP analysis was successfully performed on a total of 124 samples ( 52 from the experiment 1 and 72 from the experiment 2), all of which produced a peculiar fingerprint profile. As for the experiment 1 , the primer combinations produced a total of 154 polymorphic fragments, 84 from the famEcoRI ${ }_{(T A C)} / \mathrm{Msel}_{(A T G)}$ and 70 from the hexEcoRl $\mathrm{ACC}_{(\mathrm{AC})} / \mathrm{Msel}_{(\mathrm{ATG})}$. A total of 191 fragments were obtained for the experiment 2, 88 from the famEcoRI $\mathrm{TAC}_{(\mathrm{AC})} / \mathrm{Msel}_{(\mathrm{ATG})}$ and 103 from the hexEcoRI $_{(A C G)} / \mathrm{Msel}_{(A T G)}$. The overall level of genetic diversity within sampling groups was higher for the controls than the treatments ( 0.257 and 0.190 respectively). Concerning the experiment 1 , the levels of genetic diversity within each sampling group varied from 0.256 to 0.161 , for TREAT1 and TREAT10 respectively (Table 2 ). 
Table 2

Number of analyzed individuals (n. sample) for each sampling group (ID) for both experiments. Cadmium concentration (Cd $(\mathrm{mg} / \mathrm{L}))$, days of exposure (Time (days)) and within-sampling group average genetic diversity $(\mathrm{He})$ were also reported.

\begin{tabular}{|lllll|}
\hline ID & n. sample & Cd (mg/L) & Time (days) & He \\
\hline Experiment 1 & & & & \\
\hline CONT & 12 & 0 & 7 & 0.23573 \\
\hline TREAT1 & 10 & 1 & 7 & 0.25599 \\
\hline TREAT2.5 & 12 & 2.5 & 7 & 0.23731 \\
\hline TREAT5 & 11 & 5 & 7 & 0.19126 \\
\hline TREAT10 & 7 & 10 & 7 & 0.16079 \\
\hline Experiment 2 & & & & \\
\hline CONT0G & 8 & 0 & 0 & 0.24515 \\
\hline CONT3G & 8 & 0 & 3 & 0.27459 \\
\hline CONT7G & 8 & 0 & 7 & 0.23887 \\
\hline CONT14G & 8 & 0 & 14 & 0.21895 \\
\hline CONT21G & 8 & 0 & 21 & 0.32592 \\
\hline TREAT3G & 8 & 2.5 & 3 & 0.15345 \\
\hline TREAT7G & 8 & 2.5 & 7 & 0.15919 \\
\hline TREAT14G & 8 & 2.5 & 14 & 0.17175 \\
\hline TREAT21G & 8 & 2.5 & 21 & 0.19042 \\
\hline
\end{tabular}

The genomic template stability analysis showed a consistent reduction of the percentage of polymorphic loci for the group of treated samples excluding TREAT1 (Fig. 3A, $p<0.001$ ). The number of SpL were higher for the group formed by controls and TREAT1 compared to the TREAT2.5, TREAT5 and TREAT10 (24 and 8 respectively). The genetic diversity within each sampling group varied from 0.326 for CONT21G and 0.153 for T03G in the experiment 2 (Table 2). The analysis of genomic template stability confirmed the results of experiment 1 , showing a reduction of the percentage of polymorphic loci for the treated group (Fig. 3B, $\mathrm{p}<0.001$ ). The number of $\mathrm{SpL}$ were 17 for the control group, whereas no specific loci were showed for the treated ones.

As for the AMOVA, the greatest percentage of the total genetic variation was due to among sampling group differences $(52.38 \%, \mathrm{p}<0.001)$. Among all hypothetical cluster of sampling groups, the one formed by control and the treated with $1 \mathrm{mg} \mathrm{L}^{-1}$ of Cd (CONT-TREAT1), and the group of plant exposed to 2.5, 5 and $10 \mathrm{mg} \mathrm{L}^{-1}$ (TREAT2.5- TREAT5- TREAT10), accounted for the highest percentage of among-groups 
variation $63.38 \% ; \mathrm{P}<0.0001$; Table 3). The higher level of total genetic variation in the experiment 2 was for within sampling group $(74.8 \%, p<0.022)$. Among the hypothetical grouping of sampling groups, control plants vs treated plants accounted for the high percentage of variation among groups (see Table 3).

Table 3

Analysis of molecular variance. The table shows: degrees of freedom (d.f.), sum of squared deviations $(\mathrm{Sq})$, variance component estimates $(\mathrm{Vc})$, percentages of total variance contributed by each component (\% of variation).

\begin{tabular}{|lllll|l|}
\hline Experiment 1 & d.f. & Sq & Vc & \% of variation \\
\hline Source of variation & 1 & 780.45 & 29.95 & 63.38 \\
\hline Among grouping of sampling groups & 3 & 59.87 & 0.29 & 0.61 \\
\hline Among sampling groups within groupings & & 47 & 799.63 & 17.01 & 36.00 \\
\hline Within sampling groups & 51 & 1639.94 & 47.25 & \\
\hline Total & & & & \\
\hline Experiment 2 & d.f. & Sq & Vc & $\%$ of variation \\
\hline Source of variation & 1 & 197.74 & 3.76 & 12.19 \\
\hline Among grouping of sampling groups & 7 & 447.13 & 5.25 & 17.00 \\
\hline Among sampling groups within groupings & 7 & 63 & 1377.88 & 21.87 & 70.81 \\
\hline Within sampling groups & 71 & 2022.74 & 30.89 & \\
\hline Total & & & & \\
\hline
\end{tabular}

\section{Discussion}

Our results provided useful and novel information for the direct quantification of the genotoxic effect of Cd-polluted waters by using AFLP fingerprinting on M. aquaticum.

Root and shoot growth was reduced in the experiment 1 at already $1 \mathrm{mg} \mathrm{L}^{-1} \mathrm{Cd}(8,89 \mu \mathrm{M})$, in agreement with results from other studies showing that the first symptoms of toxicity were typically under solutions containing $\mathrm{Cd}$ at low micromolar concentrations (see for example Andresen et al. 2013; Kovacik et al. 2017). Shoots and roots showed the same susceptibility to the presence of $C d$, as demonstrated by the similar values of their $\mathrm{EC}_{50 \text { ext }}$. Despite this, the two organs did not show the same level of $\mathrm{Cd}$ accumulation, thus suggesting different sensibility to the internal metal concentrations. Since $\mathrm{Cd}$ accumulation was higher in roots than in shoots, this latter organ proved to be more susceptible to $\mathrm{Cd}$ toxicity (as quantified by its significantly lower $\mathrm{EC}_{50 \mathrm{int}}$ in respect to the one of the roots). This outcome cannot be ignored in optimizing the tests, therefore shoots were chosen for the genotoxic analysis, to get more reliable results on the effect of $\mathrm{Cd}$. For the devising of eco-toxicological tests, previous screenings 
need to be undertaken to choose the most suitable organ. Generally, roots of land plants are used for practical reasons (Aksoy, 2017), thus raising doubts not only about their validity as the most sensitive part but also on the reliability of the exposure methods. Obviously, plants exposed to Cd-contaminated waters are mostly the macrophytes, with the whole body in contact with the pollutant. This feature cannot be neglected and makes the effects of the metal on such organisms hardly comparable with those on land plants.

Comparing the biometrical data to the molecular information, the first treatment concentration at which both the effect on growth and on DNA variation were contemporarily significant was as high as $2.5 \mathrm{mg}$ $\mathrm{L}^{-1}$. This result indicated that metal-induced depression of plant growth did not necessarily imply a more dangerous genotoxic effect in the low Cd concentration zone. Precisely, the DNA-fingerprinting approach revealed a consistent separation of sampling groups in terms of the partition of molecular variance at treatments with $2.5,5$ and $10 \mathrm{mg} \mathrm{L}^{-1}$ of $\mathrm{Cd}$. The plausible effect of $\mathrm{Cd}$ in variating the AFLP profiles among samples was also corroborated by the identification of 24 loci, that were distinguished as specific for the group formed by control plants and plants treated at lower concentration $\left(1 \mathrm{mg} \mathrm{L}^{-1}\right)$. Eight loci were instead specific for the samples treated at 2.5, 5 and $10 \mathrm{mg} \mathrm{L}^{-1}$. Cadmium treatment seemed to affect the levels of genetic diversity of the sampling groups also, since lower average genetic diversity values were shown for those sampling groups treated with the highest $\mathrm{Cd}$ concentrations (e.g. 5 and 10 $\mathrm{mg} \mathrm{L}^{-1}$ ). Moreover, the reduction of polymorphisms was detected for the treated group, concurring to register a different profile in AFLP fingerprinting in respect to the control plants. As revealed from other studies, the variation in genetic profiles, the appearance or disappearance of new specific loci, and the reduction of the genomic template stability, may be the consequence of i) genomic rearrangements in the primers binding sites, or ii) structural changes in the DNA sequences, led by the genotoxic effect of different organic or inorganic substances (Liu et al. 2005; Rocco et al. 2014).

Given the above-mentioned double result of the concentration 2.5, the effect of this same Cd amount on growth, accumulation and AFLP profiles was evaluated in a time-dependent experiment.

Concerning plant elongation and metal concentration in roots and shoots, experiment 2 confirmed the same results observed in the concentration-dependant one. The two organs showed a similar Cd-induced decrease in growth (around 70\% reduction of length increment at the end of the experiment for both the organs), nonetheless shoots displayed a lower metal accumulation than roots and, accordingly, a higher sensitivity to the presence of the metal inside its tissues. Therefore, shoots confirmed to represent a better candidate than roots for eco-toxicological tests. In both organs, a significant Cd-induced decrease in growth was present after seven days. However, plant $\mathrm{Cd}$ accumulation occurred already after three days, but apparently at harmless concentration for growth. Comparing to the molecular data, again an out-ofsync scenario appeared, this time with an unexpected vice-versa. Actually, Cd treatment was able to induce variation in the DNA fingerprinting profiles, evidencing a genotoxic effect, already after three days and without a significant growth depression. Therefore, for shorter times and higher doses in respect to the critical threshold of experiment 1, the harmful effect of the metal on the plant genome was already 
present, thus corroborating the unreliability of eco-toxicological tests based only on plant growth already supposed by the results of experiment 1. Particularly, the AMOVA analysis showed that the large portion of the molecular variance is significantly explained by keeping the control samples separated from the treated ones. Also, the identification of 17 loci specific for the control plants confirmed that the genotoxic effect of $2.5 \mathrm{mg} \mathrm{L}^{-1} \mathrm{Cd}$ treatment may become evident from the first days of the experiment. As in previous studies, DNA-fingerprinting profiles generated from plants exposed to ascending concentrations of phytotoxic inorganic substances revealed appearing and disappearing bands in comparison to control samples (Liu et al. 2009). Moreover, in our experiment, AFLP profiles variation induced by time-dependent Cd exposure was reflected by changes in DNA profiles and by reduction of the genome template stability after only three days, indicating a high-sensitivity of the molecular approach in the identification of genotoxic effects of medium-low concentration of $\mathrm{Cd}$ in water. Our results corroborate other earlier studies (Labra et al. 2003) reporting the high sensitivity of molecular approach than classic genotoxic trials, since they are capable of detecting DNA changes that may not manifest themselves as biometrical mutations.

\section{Conclusions}

Myriophyllum aquaticum revealed to be a suitable model system for the investigation of Cd genotoxicity through AFLP fingerprinting profile. Our joint experiments in concentration and in time allowed to identify two of the combinations of dose $\left(2.5 \mathrm{mg} \mathrm{L}^{-1}\right)$ and exposure ( 3 days) for Cd-polluted waters beyond which concern for environmental genotoxic danger could arise. Moreover, our results showed that a metal-induced reduction of plant growth does not necessarily imply a DNA damage and, more worryingly, vice versa. Consequently, there is the urgent need to implement those more classic eco-toxicological tests based only on plant growth. Such tests, despite being easy to use and cost-effective, can underestimate the risk associated to not detected Cd-induced mutations in the genome of living organisms, that can have concerning implications in the long term.

\section{Declarations}

- Ethics approval and consent to participate: Not applicable

- Consent for publication: Not applicable

- Availability of data and materials: The datasets used and/or analysed during the current study are available from the corresponding author on reasonable request.

- Competing interests: The authors declare that they have no competing interests

- Funding: Research grants to AC and CG from the University of Florence are acknowledged.

- Authors' contributions: AC: Conceptualization, Methodology, Formal analysis, Investigation, Resources, Data Curation, Writing - Original Draft, Visualization, Supervision, Funding acquisition. IC: Methodology, Formal analysis, Investigation, Data Curation, Writing - Original Draft, Writing - Review \& Editing. LL: Conceptualization, Investigation, Writing - Review \& Editing. MBC Formal analysis, 
Writing - Review \& Editing, Visualization. CG: Conceptualization, Resources, Writing - Original Draft, Writing - Review \& Editing, Supervision, Funding acquisition. All authors read and approved the final manuscript.

- Acknowledgements: Authors are grateful to Elisa Barelli and Alice Pinzauti for their contribution in the preliminary experimental work.

- Authors' information (optional): Not applicable

\section{References}

1. Aina R, Labra M, Fumagalli P, Vannini C, Marsoni M, Cucchi U, Bracale M, Sgorbati S, Citterio S (2007) Thiol-peptide level and proteomic changes in response to cadmium toxicity in Oryza sativa $L$ roots. Env Exp Bot 59:381-392. https://doiorg/101016/jenvexpbot200604010

2. Aksoy Ö (2017) Detection of Environmental Mutagens Through Plant Bioassays. Plant EcologyTraditional Approaches to Recent Trends. InTech Open, 9-23. https://doiorg/10.5772/intechopen.69274

3. Ali H, Khan E, Sajad MA (2013) Phytoremediation of heavy metals-Concepts and applications. Chemosphere 91:869-881. https://doiorg/101016/jchemosphere201301075

4. Andresen E, Mattusch J, Wellenreuther G, Thomas G, Arroyo Abad U, Küpper H (2013) Different strategies of cadmium detoxification in the submerged macrophyte Ceratophyllum demersum L. Metallomics 5:1377-1386. https://doiorg/101039/c3mt00088e

5. Apel K, Hirt H (2004) Reactive oxygen species: metabolism, oxidative stress, and signal transduction. Annu Rev Plant Biol 55:373-399. https://doiorg/101146/annurevarplant55031903141701

6. ATSDR U (2007) CERCLA priority list of hazardous substances. http://wwwatsdrcdcgov/cercla/07listhtml

7. ATSDR U (2015) Toxicologial Profiles, Toxic Substances Portal. http://wwwatsdrcdcgov/toxprofiles/index asp

8. Barzanti R, Colzi I, Arnetoli M, Gallo A, Pignattelli S, Gabbrielli R,Gonnelli C (2011) Cadmium phytoextraction potential of different Alyssum species. J Hazard Mater 196:66-72. https://doiorg/101016/jjhazmat201108075

9. Bettarini I, Colzi I, Coppi A, Falsini S, Echevarria G, Pazzagli L, Selvi F, Gonnelli C (2019) Unravelling soil and plant metal relationships in Albanian nickel hyperaccumulators in the genus Odontarrhena (syn Alyssum sect Odontarrhena, Brassicaceae). Plant Soil 440(1):135-149. https://doiorg/101007/s11104-019-04077-y

10. Beyersmann D, Hartwig A (2008) Carcinogenic metal compounds: recent insight into molecular and cellular mechanisms. Arch toxicol 82(8):493-512. https://doiorg/101007/s00204-008-0313-y

11. Brack W, Dulio V, Agerstrand M, Allan I, Altenburger R, Brinkmann M et al. (2017) Towards the review of the European Union Water Framework Directive: Recommendations for more efficient assessment 
and management of chemical contamination in European surface water resources. Sci Total Environ 576:720-737. https://doiorg/101016/jscitotenv201610104

12. Caballero A, García-Pereira MJ, Quesada H (2013) Genomic distribution of AFLP markers relative to gene locations for different eukaryotic species. BMC genomics, 14, 528.

https://doiorg/101186/1471-2164-14-528

13. Ceschin S, Bellini A, Scalici M (2020) Aquatic plants and ecotoxicological assessment in freshwater ecosystems: a review. Environ Sci \& Pollut Res 1-14 https://doiorg/101007/s11356-020-11496-3

14. Colzi I, Doumett S, Del Bubba N, Fornaini J, Arnetoli M, Gabbrielli R, Gonnelli C (2011) On the role of the cell wall in the phenomenon of copper tolerance in Silene paradoxa L. Env Exp Bot 72(1):77-83. https://doiorg/101016/jenvexpbot201002006

15. Colzi I, Rocchi S, Rangoni M, Del Bubba M, Gonnelli C (2014) Specificity of metal tolerance and use of excluder metallophytes for the phytostabilization of metal polluted soils: the case of Silene paradoxa L. Environ Sci \& Pollut Res 21(18):10960-10969. https://doiorg/101007/s11356-014-3045y

16. Colzi I, Lastrucci L, Rangoni M, Coppi A, Gonnelli C (2018) Using Myriophyllum aquaticum (Vell) Verdc to remove heavy metals from contaminated water: better dead or alive? J Environ Manag 213:320-328. https://doiorg/101016/jjenvman201802074

17. Coppi A, Lastrucci L, Cappelletti D, Cerri M, Ferranti F, Ferri V, Foggi B, Gigante D, Venanzoni R, Viciani D, Selvaggi R, Reale L (2018) AFLP Approach Reveals Variability in Phragmites australis: Implications for Its Die-Back and Evidence for Genotoxic Effects. Front Plant Sci 9, 386. https://doiorg/103389/fpls201800386

18. Excoffier L, Smouse PE, Quattro JM (1992) Analysis of molecular variance inferred from metric distances among DNA haplotypes: application to human mitochondrial DNA restriction data. Genetics 131(2):479-491. PMID: 1644282

19. Galardi F, Corrales I, Mengoni A, Pucci S, Barletti L, Barzanti R, Arnetoli M, Gabbrielli R, Gonnelli C (2007) Intra-specific differences in nickel tolerance and accumulation in the Ni-hyperaccumulator Alyssum bertolonii. Environ Exp Bot 60:377-384. https://doiorg/101016/jenvexpbot200612011

20. Hassan SH, Van Ginkel SW, Hussein MA, Abskharon R, Oh SE (2016) Toxicity assessment using different bioassays and microbial biosensors. Environ Int 92:106-118. https://doiorg/101016/jenvint201603003

21. Hossain Z, Huq F (2002) Studies on the interaction between $\mathrm{Cd}^{2+}$ ions and nucleobases and nucleotides. J Inorg Biochem 90(3-4): 97-105. https://doiorg/101016/S0162-0134(02)00411-7

22. IARC (International Agency for Research on Cancer) (2016) IARC monographs on the evaluation of carcinogenic risks to humans. Volumes 1-115. https://monographsiarcwhoint/list-of-classifications/

23. Jin YH, Clark AB, Slebos RJ, Al-Refai H, Taylor JA, Kunkel TA, Resnick MA, Gordenin DA (2003) Cadmium is a mutagen that acts by inhibiting mismatch repair. Nat Genet 34(3):326-329. https://doiorg/101038/ng1172 
24. Khan MA, Ghouri AM (2011) Environmental pollution: its effects on life and its remedies. Journal of Arts, Science \& Commerce 2(2):276-285.

25. Kleinjans JC, van Schooten FJ (2002) Ecogenotoxicology: the evolving field. Environ Toxicol Pharmacol 11(3-4):173-179. https://doiorg/101016/S1382-6689(01)00115-6

26. Kováčik J, Babula P, Hedbavny J (2017) Comparison of vascular and non-vascular aquatic plant as indicators of cadmium toxicity. Chemosphere 180:86-92.

https://doiorg/101016/jchemosphere201704002

27. Labra M, Di Fabio T, Grassi F, Regondi SMG, Bracale M, Vannini C, Agradi E (2003) AFLP analysis as biomarker of exposure to organic and inorganic genotoxic substances in plants. Chemosphere 52(7):1183-1188. https://doiorg/101016/S0045-6535(03)00367-9

28. Lastrucci L, Lazzaro L, Dell'Olmo L, Foggi B, Cianferoni F (2018) Impacts of Myriophyllum aquaticum invasion in a Mediterranean wetland on plant and macro-arthropod communities. Plant Biosyst 152(3):427-435. https://doiorg/101080/1126350420171303002

29. Liu W, Li PJ, Qi XM, Zhou QX, Zheng L, Sun TH, Yang YS (2005) DNA changes in barley (Hordeum vulgare) seedlings induced by cadmium pollution using RAPD analysis. Chemosphere 61(2):158-67. https://doiorg/101016/jchemosphere200502078

30. Liu W, Yang YS, Li PJ, Zhou QX, Xie LA, Han YP (2009) Risk assessment of cadmium-contaminated soil on plant DNA damage using RAPD and physiological indices. J Hazard Mater 161(2-3):878-883. https://doiorg/101016/jjhazmat200804038

31. Meudt HM, Clarke AC (2007) Almost forgotten or latest practice? AFLP applications, analyses and advances. Trends Plant Sci 12(3):106-117. https://doiorg/101016/jtplants200702001

32. Monteiro MS, Lopes T, Mann RM, Paiva C, Soares AMVM, Santos C (2009) Microsatellite instability in Lactuca sativa chronically exposed to cadmium. Mutat Res Genet Toxicol Environ Mutagen 672(2):90-94. https://doiorg/101016/jmrgentox200810012

33. OECD (2014) OECD TG 238 Guidelines for the Testing of Chemicals Sediment-free Myriophyllum spicatum Toxicity Test. https://doiorg/101787/20745761

34. Ohe T, Watanabe T, Wakabayashi K (2004) Mutagens in surface waters: a review. Mutat Res 567(23):109-149. https://doiorg/101016/jmrrev200408003

35. Orchard AE (1981) A revision of South American Myriophyllum aquaticum (haloragaceae), and its repercussions on some Australian and North American species. Brunonia 4.1:27-65. https://doiorg/101071/BRU9810027

36. Panda BB, Panda KK (2002) Genotoxicity and mutagenicity of metals in plants. Physiology and Biochemistry of Metal Toxicity and Tolerance in Plants, pp 395-414. https://doiorg/101007/978-94017-2660-3_15

37. Qi XM, Li PJ, Wan LIU, Xie LJ (2006) Multiple biomarkers response in maize (Zea mays L) during exposure to copper. J Environ Sci 18(6):1182-1188. https://doiorg/101016/S1001-0742(06)60059-4

38. Rocco L, Valentino IV, Scapigliati G, Stingo V (2014) RAPD-PCR analysis for molecular characterization and genotoxic studies of a new marine fish cell line derived from Dicentrarchus 
labrax. Cytotechnology 66(3):383-393. https://doiorg/101007/s10616-013-9586-y

39. Saitou N, Nei M (1987) The neighbor-joining method: a new method for reconstructing phylogenetic trees. Mol Biol Evol 4(4):406-25. https://doiorg/101093/oxfordjournalsmolbeva040454

40. Salameh E, Shteiwi M, Al Raggad M (2018) Waste water treatment. In: Singh PV, editor. Water Resources of Jordan. USA: Springer. p.87-110

41. Schneider S, Roessli D, Excoffier $L$ (2000) Arlequin: a software for population genetics data analysis Version 2000. http://anthrounigech/arlequin

42. Schwarzenbach RP, Escher BI, Fenner K, Hofstetter TB, Johnson CA, Von Gunten U, Wehrli B (2006) The challenge of micropollutants in aquatic systems. Science 313:1072-1077. https://doiorg/101126/science1127291

43. Slatkin M (1995) A measure of population subdivision based on microsatellite allele frequencies. Genetics 139:457-462. https://doiorg/101093/genetics/1391457

44. Surgun $\mathrm{Y}$, İşkil R, Ceylan $\mathrm{K}$, Ceylan $\mathrm{Y}$ (2018) Genotoxicity assessment of heavy metals $(\mathrm{Zn}, \mathrm{Cr}, \mathrm{Pb})$ on strawberry plants using rapd assay. Fresenius Envir Bulletin 27(4):2483-2491. http://hdlhandlenet/11772/1665

45. Tamura K, Filipski A, Kumar S (2013) MEGA6: Molecular Evolutionary Genetics Analysis Version 60. Mol Biol Evol 30(12):2725-2729. https://doiorg/101093/molbev/mst197

46. US Environmental Protection Agency (US EPA) (2015) Regulated drinking water contaminants. https://wwwepagov/sdwa/drinking-water-contaminant-human-health-effects-information

47. Valverde M, Trejo C, Rojas E (2001) Is the capacity of lead acetate and cadmium chloride to induce genotoxic damage due to direct DNA-metal interaction? Mutagenesis 16(3):265-270. https://doiorg/101093/mutage/163265

48. Wang L, Gao Y, Wang X, Qin Z, Liu B, Zhang X, Wang G (2021) Warming enhances the cadmium toxicity on macrophytes Myriophyllum aquaticum (Vell.) Verd. seedlings. Environ Poll 268: 115912. https://doi.org/10.1016/j.envpol.2020.115912

49. Zhu Y, Costa M (2020) Metals and molecular carcinogenesis. Carcinogenesis 41: 1161-1172. https://doiorg/10.1093/carcin/bgaa076

\section{Figures}




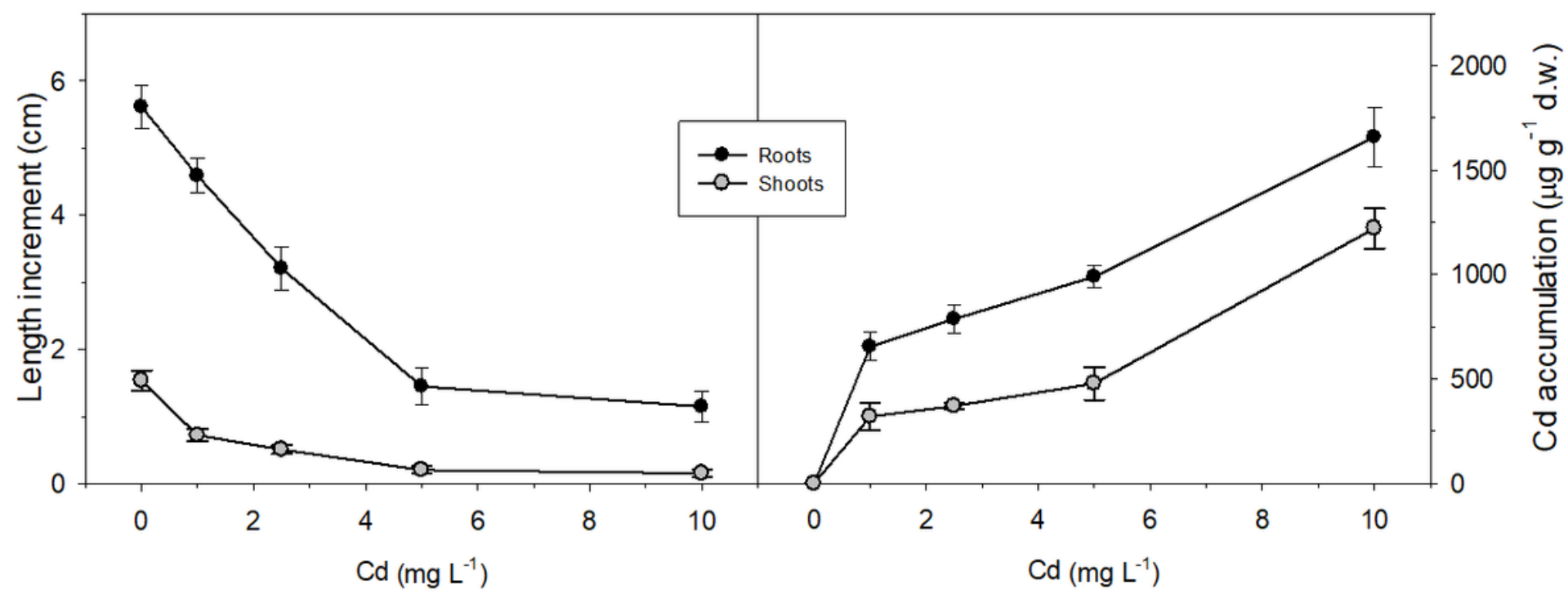

Figure 1

Results of experiment 1: (A) Root and shoot increment in length (cm) and (B) Cd accumulation in roots and shoots ( $\mu \mathrm{g} \mathrm{g-1} \mathrm{d.w.)} \mathrm{of} \mathrm{M.} \mathrm{aquaticum} \mathrm{after} \mathrm{exposure} \mathrm{to} \mathrm{increasing} \mathrm{Cd}$ concentrations for 7 days. Values are mean \pm standard error. The significant effect of metal concentration in respect to control is indicated by asterisks $\left({ }^{\star} p<0.05 ;{ }^{* *} p<0.01 ;{ }^{* *} p<0.001\right)$ 


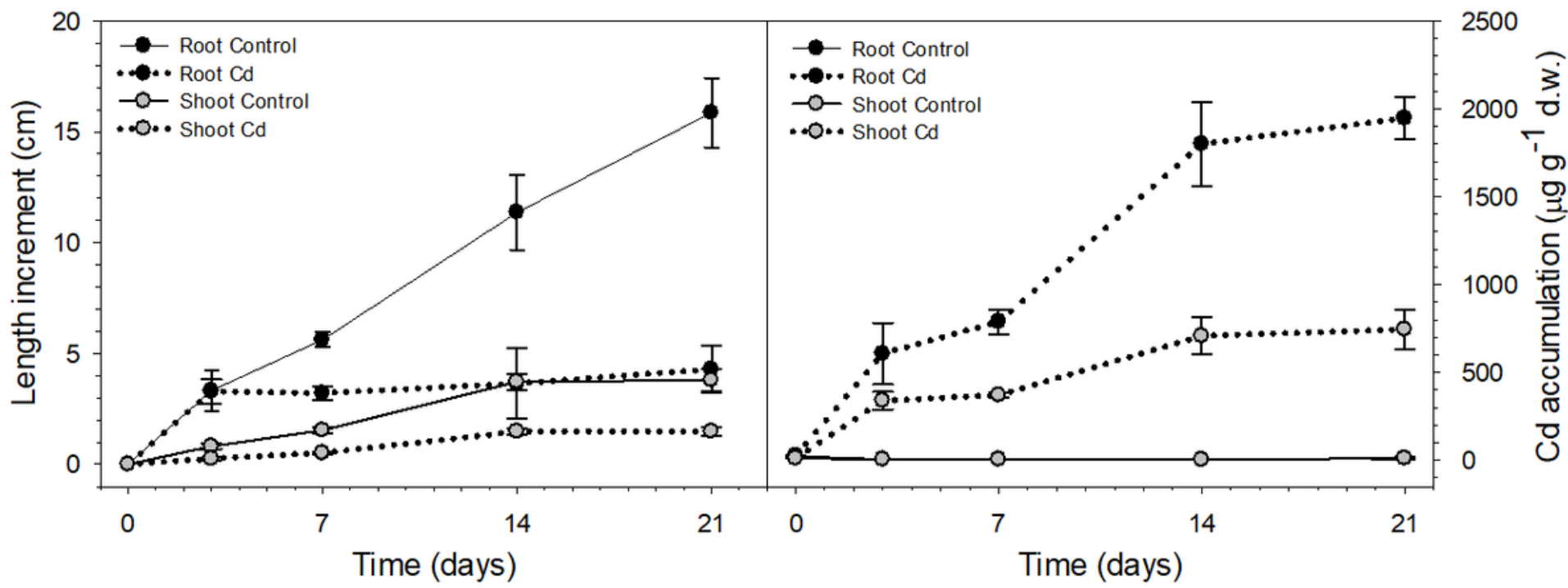

Figure 2

Results of experiment 2: (A) Root and shoot increment in length ( $\mathrm{cm}$ ) and (B) Cd accumulation in roots and shoots ( $\mu \mathrm{g} \mathrm{g}-1 \mathrm{~d}$.w.) of $\mathrm{M}$. aquaticum after different exposure time (0-21 days) at $2.5 \mathrm{mg} \mathrm{L-1} \mathrm{Cd}$. Values are mean \pm standard error. The significant effect of $\mathrm{Cd}$ treatment in respect to the respective control is indicated by asterisks ( ${ }^{\star} p<0.05 ;{ }^{* \star} p<0.01 ; * \star \star p<0.001$ )
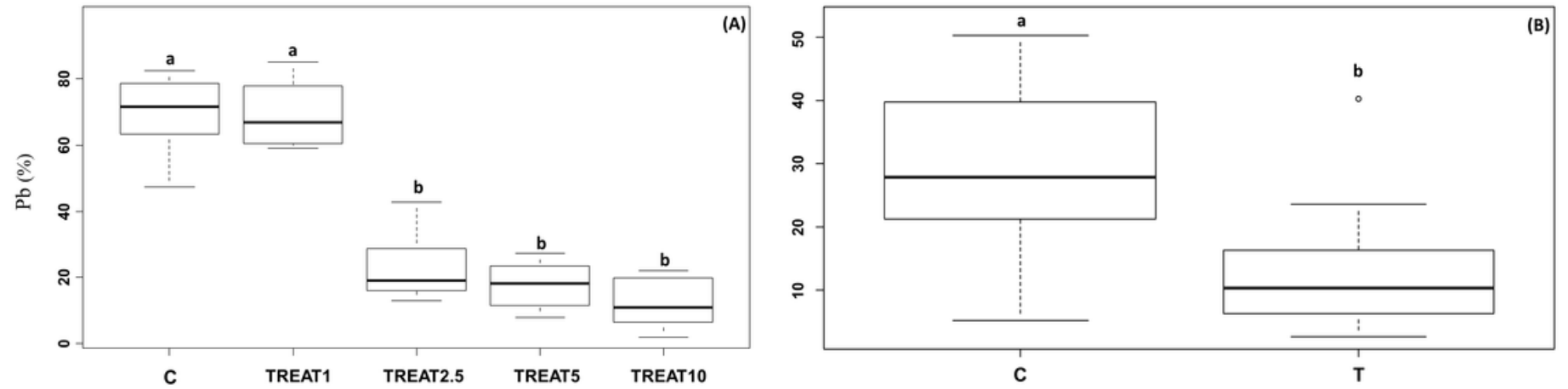

Treatment

Figure 3 
Boxplot showing the differences in percentage of polymorphic bands composition $\mathrm{Pb}(\%)$ for the experiment $1(A)$ and experiment $2(B)$. The significant differences among treatment and control are indicated by letters 